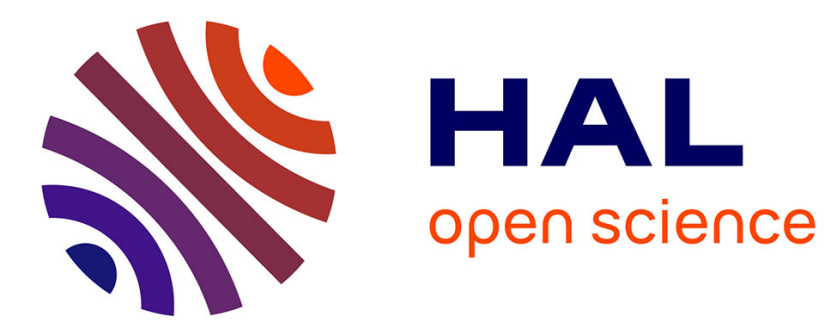

\title{
A structural and magnetic study of Nd5Fe2B6 and Nd5Fe2B6D4.1
}

Sophie Tencé, Alain Wattiaux, Mathieu Duttine, Rodolphe Decourt, Olivier

Isnard

\section{- To cite this version:}

Sophie Tencé, Alain Wattiaux, Mathieu Duttine, Rodolphe Decourt, Olivier Isnard. A structural and magnetic study of Nd5Fe2B6 and Nd5Fe2B6D4.1. Journal of Alloys and Compounds, 2017, 693, pp.887-894. 10.1016/j.jallcom.2016.09.243 . hal-01415895

\section{HAL Id: hal-01415895 \\ https://hal.science/hal-01415895}

Submitted on 13 Dec 2016

HAL is a multi-disciplinary open access archive for the deposit and dissemination of scientific research documents, whether they are published or not. The documents may come from teaching and research institutions in France or abroad, or from public or private research centers.
L'archive ouverte pluridisciplinaire HAL, est destinée au dépôt et à la diffusion de documents scientifiques de niveau recherche, publiés ou non, émanant des établissements d'enseignement et de recherche français ou étrangers, des laboratoires publics ou privés. 


\title{
A structural and magnetic study of $\mathrm{Nd}_{5} \mathrm{Fe}_{2} \mathrm{~B}_{6}$ and $\mathrm{Nd}_{5} \mathrm{Fe}_{2} \mathrm{~B}_{6} \mathrm{D}_{4.1}$
}

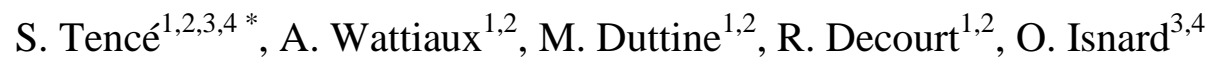 \\ ${ }^{1}$ CNRS, ICMCB, UPR 9048, F-33600 Pessac, France \\ ${ }^{2}$ Univ. Bordeaux, ICMCB, UPR 9048, F-33600 Pessac, France \\ ${ }^{3}$ Univ. Grenoble Alpes, Inst NEEL, F-38042 Grenoble, France \\ ${ }^{4}$ CNRS, Inst NEEL, F-38042 Grenoble, France
}

${ }^{*}$ Corresponding author: E-mail address: tence@icmcb-bordeaux.cnrs.fr

\begin{abstract}
We investigated the structural and magnetic properties of the boride $\mathrm{Nd}_{5} \mathrm{Fe}_{2} \mathrm{~B}_{6}$ and of the deuteride $\mathrm{Nd}_{5} \mathrm{Fe}_{2} \mathrm{~B}_{6} \mathrm{D}_{4.1}$ by means of magnetization and specific heat measurements, Mössbauer spectroscopy and neutron powder diffraction. In $\mathrm{Nd}_{5} \mathrm{Fe}_{2} \mathrm{~B}_{6} \mathrm{D}_{4.1}$, deuterium atoms are located in two inequivalent interstitial sites: one octahedral D1 [Nd6] and one tetrahedral D2 $[\mathrm{Nd} 3 \mathrm{Fe}]$, both avoiding $\mathrm{B}$ as near neighbor. This insertion induces a pronounced anisotropic unit cell expansion along the $c$-axis. While the $\mathrm{Nd}_{5} \mathrm{Fe}_{2} \mathrm{~B}_{6}$ compound exhibits a magnetic ordering below about $68 \mathrm{~K}$, the deuteride exhibits a lower ordering temperature of about $21 \mathrm{~K}$ as a consequence of $\mathrm{D}$ insertion in the $\mathrm{Nd}$ environment. For both compounds powder neutron diffraction investigations have evidenced a ferromagnetic structure with magnetic moments along the $c$-axis. However, in the deuteride, the $\mathrm{Nd}$ magnetic moments values are reduced and that of $\mathrm{Fe}$ vanishes. ${ }^{57} \mathrm{Fe}$ Mössbauer spectroscopy confirms the existence of a small ordered magnetic moment on iron in $\mathrm{Nd}_{5} \mathrm{Fe}_{2} \mathrm{~B}_{6}$ and the presence of two environments for $\mathrm{Fe}$ in the deuteride.
\end{abstract}

Key words: Boron hydride, hydrogenation, magnetic measurements, ${ }^{57} \mathrm{Fe}$ Mössbauer spectroscopy, neutron diffraction, magnetic structure

\section{Introduction}


The discovery of the excellent magnetic properties of $\mathrm{Nd}_{2} \mathrm{Fe}_{14} \mathrm{~B}$ for applications as a permanent magnet material with high energy product has motivated the studies of the ternary phase diagrams $R$-Fe-B ( $R=$ Rare-earth). In this way, new borides of $\operatorname{Pr}_{5-\mathrm{x}} \mathrm{Co}_{2+\mathrm{x}} \mathrm{B}_{6}$-type structure containing iron and cobalt have been obtained in 1986 by Dub et al. for $R=\mathrm{Y}$, La, $\mathrm{Ce}, \mathrm{Pr}, \mathrm{Nd}, \mathrm{Sm}, \mathrm{Eu}, \mathrm{Gd}, \mathrm{Tb}, \mathrm{Dy}, \mathrm{Ho}, \mathrm{Er}, \mathrm{Tm}, \mathrm{Yb}, \mathrm{Lu}$ [1]. The crystal structures of these borides $R_{5} T_{2} \mathrm{~B}_{6}(T=$ transition metal) have been determined previously by $\mathrm{X}$-ray diffraction and the existence of a homogeneity range has been stated for some of them $[1,2]$. They crystallize in the trigonal space group $R-3 m$ with the unit cell parameters a $\approx 5.4 \AA$ and $\mathrm{c} \approx 23$ $\AA$. The structure consists of a stacking of alternated $\left[R_{3}\right]$ and $\left[R_{2} T_{2} \mathrm{~B}_{6}\right]$ blocks along the c-axis, yielding $R_{5} T_{2} \mathrm{~B}_{6}$ as final composition of the stoichiometric boride. The $\left[R_{2} T_{2} \mathrm{~B}_{6}\right]$ layer contains a flat net of boron atoms which is surrounded by the iron atoms as nearest neighbors. Thus, the structure possesses 3 different sites for $R$, one for $T$ and one for $\mathrm{B}$. The homogeneity range for some compounds comes from the possible substitution of the transition metal for the rare earth on the R1 and R3 sites.

It is possible to synthesize the hydrides $R_{5} T_{2} \mathrm{~B}_{6} \mathrm{H}_{\mathrm{x}}$ from the $R_{5} T_{2} \mathrm{~B}_{6}$ borides by heating them in hydrogen gas [3-6]. Stable hydrides are formed in rather mild hydrogenation conditions, namely for a temperature up to $200^{\circ} \mathrm{C}$ and for a hydrogen pressure of about 1 bar. Much higher temperatures and pressures conditions provoke the disproportionation of the $R_{5} T_{2} \mathrm{~B}_{6}$ boride. Hydrogen insertion yields an anisotropic volume expansion due to the strong increase of the $c$ parameter whereas $a$ remains unchanged or decreases slightly. So far the absorptiondesorption behavior of hydrogen in those borides has been widely studied [3-6] but the crystal structure of the hydrides has never been determined precisely. The deuterium atoms can be situated in different interstices in the host structure such as R6, R4, R3T, R2TB or R2B2 interstices. Besides, their magnetic properties have been barely measured since only the diminution of the Curie temperature of $\mathrm{Nd}_{5} \mathrm{Fe}_{2} \mathrm{~B}_{6}$ and $\mathrm{Gd}_{5} \mathrm{Fe}_{2} \mathrm{~B}_{6}$ upon hydrogen uptake has been reported $[3,7]$. Indeed, $\mathrm{T}_{\mathrm{C}}$ decreases from 67 to $20 \mathrm{~K}$ for the $\mathrm{Nd}$ compound and from 74 to $47 \mathrm{~K}$ for the $\mathrm{Gd}$ one whereas the Curie temperature of other ternary $R$-Fe-B boride like $R_{2} \mathrm{Fe}_{14} \mathrm{~B}$ ferromagnets increases upon hydrogenation [8].

The aim of this work is to study the influence of hydrogenation on the magnetic properties and structure of $\mathrm{Nd}_{5} \mathrm{Fe}_{2} \mathrm{~B}_{6}$. For this, we have prepared specific samples of $\mathrm{Nd}_{5} \mathrm{Fe}_{2} \mathrm{~B}_{6}$ and $\mathrm{Nd}_{5} \mathrm{Fe}_{2} \mathrm{~B}_{6} \mathrm{D}_{4.1}$ for neutron diffraction with isotopic ${ }^{11} \mathrm{~B}$ and deuterium to avoid the high absorption of natural boron and the high incoherent scattering of hydrogen. In this paper, we present magnetization and specific heat measurements, ${ }^{57} \mathrm{Fe}$ Mössbauer spectroscopy and 
neutron powder diffraction which allows us to locate the deuterium atoms and determine the magnetic structure of $\mathrm{Nd}_{5} \mathrm{Fe}_{2} \mathrm{~B}_{6}$ and $\mathrm{Nd}_{5} \mathrm{Fe}_{2} \mathrm{~B}_{6} \mathrm{D}_{4.1}$.

\section{Experiments}

The sample with the nominal composition $\mathrm{Nd}_{5} \mathrm{Fe}_{2} \mathrm{~B}_{6}$ was prepared by melting precisely weighted amounts of high purity elements $\mathrm{Nd}, \mathrm{Fe}$ and $\mathrm{B}^{11}(99.9 \%)$ in an arc melting furnace. Isotopic boron 11 was used in order to avoid the high absorption of the neutron flux by the natural boron $\left(\sigma_{\mathrm{abs}}(\mathrm{B})=767.0\right.$ barn and $\sigma_{\mathrm{abs}}\left(\mathrm{B}^{11}\right)=0.0055$ barn $)$. Melting was performed 4-5 times to ensure a good homogeneity under a purified argon gas atmosphere. The total weight loss during the overall melting process was lower than $0.4 \mathrm{wt}$. \%. X-ray powder diffraction on the as-cast sample revealed the presence of the target boride with the minor binary impurity $\mathrm{Nd}_{2} \mathrm{~B}_{5}$. Then, the as-cast ingot was enclosed in an evacuated quartz tube and underwent a heat treatment at $1073 \mathrm{~K}$ for 3 weeks. No reaction between the sample and the quartz tube was observed. X-ray powder diffraction $\left(\mathrm{Cu}-K_{\alpha}\right.$ radiation) after annealing evidences a nearly single phased sample corresponding to $\mathrm{Nd}_{5} \mathrm{Fe}_{2} \mathrm{~B}_{6}$.

To prepare the deuteride, $\mathrm{Nd}_{5} \mathrm{Fe}_{2} \mathrm{~B}_{6}$ was firstly heated at $200^{\circ} \mathrm{C}$ under vacuum to activate the sample and then exposed to a pressure of 10 bars of $\mathrm{D}_{2}$ during several hours.

Magnetization measurements were performed using a superconducting quantum interference device (SQUID) magnetometer (Quantum Design MPMS-XL) in the temperature range $5-350 \mathrm{~K}$ and in fields up to $4.6 \mathrm{~T}$.

Heat capacity was determined with a standard relaxation method with a Quantum Design PPMS device. Sample of approximately $20 \mathrm{mg}$ was glued to the sample holder using Apiezon $\mathrm{N}$-grease. The heat capacity of the sample holder and grease was measured just before the sample was studied.

${ }^{57} \mathrm{Fe}$ Mössbauer spectra were recorded in transmission geometry using a constant acceleration Halder-type spectrometer with a room temperature ${ }^{57} \mathrm{Co}$ source ( $\mathrm{Rh}$ matrix). The velocity scale was calibrated, at room temperature, using a metal iron foil. The sample holders with polycrystalline absorbers containing about $10 \mathrm{mg} / \mathrm{cm}^{2}$ of iron were placed into a liquid Helium cryostat in order to collect ${ }^{57} \mathrm{Fe}$ Mössbauer spectra in the temperature range $4.2 \mathrm{~K}$ 293 K. Refinement of the Mössbauer hyperfine parameters was performed using homemade programs and the WinNormos ${ }^{\circledR}$ software (Wissenschaftliche Elektronik GmbH). 
Neutron diffraction experiments were performed on the high resolution two-axis powder diffractometer D1B at the Institut Laue Langevin using a wavelength of $\lambda=2.52 \AA$. The neutron detector with 1280 cells covers an angular range of $128^{\circ}$. During the neutron diffraction measurements a cylindrical vanadium sample holder of $6 \mathrm{~mm}$ inner diameter was used. The FullProf Suite program was used for nuclear and magnetic structure refinements using the Rietveld method [9].

\section{Results and discussion}

\subsection{Structural results}

Both $\mathrm{Nd}_{5} \mathrm{Fe}_{2} \mathrm{~B}_{6}$ and $\mathrm{Nd}_{5} \mathrm{Fe}_{2} \mathrm{~B}_{6} \mathrm{D}_{\mathrm{x}}$ samples were measured on D1B at the same temperature to compare their respective crystal structure parameters. The refinement of the crystal structure of $\mathrm{Nd}_{5} \mathrm{Fe}_{2} \mathrm{~B}_{6}$ at $100 \mathrm{~K}$ confirms the previous studies [1] but with only one Wyckoff position for Fe and, thus, no homogeneity range (Fig. 1 and Table 1). The first investigation of the neutron diffraction pattern of $\mathrm{Nd}_{5} \mathrm{Fe}_{2} \mathrm{~B}_{6} \mathrm{D}_{\mathrm{x}}$ at $100 \mathrm{~K}$ shows that the Bragg peaks can be indexed with the trigonal space group $R-3 m$ (see Fig. 1), meaning that there is no change in the initial rhombohedral symmetry after deuterium insertion. It is noticeable that a small amount (4 wt. \%) of non deuterated $\mathrm{Nd}_{5} \mathrm{Fe}_{2} \mathrm{~B}_{6}$ boride is still present in the sample as indicated in Figure 1. We observe that the cell parameter $a$ does not change much from 5.4430(4) to $5.4463(2) \AA(+0.06 \%)$ whereas $c$ strongly increases from $24.133(3)$ to $24.813(2) \AA(+2.8 \%)$. Therefore, the volume expansion which amounts to $+2.9 \%$ is strongly anisotropic and mainly along the $c$-axis. This evolution is consistent with that observed by Yartys et al. after hydrogenation of $\mathrm{Nd}_{5} \mathrm{Fe}_{2} \mathrm{~B}_{6}$ to obtain $\mathrm{Nd}_{5} \mathrm{Fe}_{2} \mathrm{~B}_{6} \mathrm{H}_{8.6}$ even if the final $\mathrm{H}$ content is not the same [4]. Indeed, they measured at room temperature a unit cell parameters evolution from 5.464(5) to $5.455(8) \AA$ ( $-0.16 \%)$ for $a$ and from $24.17(4)$ to $24.97(8) \AA(+3.3 \%)$ for $c$.

In the final refinement, the neodymium, iron and boron atoms were initially put at the same Wyckoff position as in the boride, the $(\mathrm{x}, \mathrm{y}, \mathrm{z})$ coordinates being then refined in the Rietveld analysis. Among the five main possible interstices it clearly appears that the deuterium atoms are mainly located in the octahedral one $\left[\mathrm{Nd}_{6}\right]$ formed by $2 \mathrm{Nd} 1,2 \mathrm{Nd} 2$ and $2 \mathrm{Nd} 3$ atoms. This site located in the position D1 $(1 / 2,0,0)$ is filled at $85 \%$. The tetrahedral interstice formed by $3 \mathrm{Nd}(\mathrm{Nd} 1, \mathrm{Nd} 2$ and $\mathrm{Nd} 3)$ and $1 \mathrm{Fe}$ atoms is also partly occupied by deuterium atoms. This second site $\left[\mathrm{Nd}_{3} \mathrm{Fe}\right]$ is in the refined position D2 $(0.203,0.026,0.0664)$ and is filled at only $13 \%$. The occupancy of these two interstices leads to $\mathrm{Nd}_{5} \mathrm{Fe}_{2} \mathrm{~B}_{6} \mathrm{D}_{4.1(2)}$ as 
deuteride formula which is fairly coherent with the mass uptake after deuterium insertion which corresponds to a D content of approximately $4.5 \mathrm{D} / \mathrm{f}$.u. The crystal structure of this deuteride determined from neutron data is depicted in the Figure 2 and the final refinement is shown on Figure 1. The structural parameters of the boride and the deuteride are gathered in Table 1 and the interatomic distances around $\mathrm{Nd}, \mathrm{Fe}$ and $\mathrm{D}$ atoms are given in Table 2 and 3. The presence of deuterium atoms in the D1 site implies D1-D1 distances which amount to $2.72 \AA$. On the other hand the D2 site is only weakly filled since it induces the existence of some too short D2-D2 distances, i.e. 0.82 (x1), 1.25 (x1), 1.80 (x2) and $2.07 \AA$ (x1), this last one being close to the critical distance $(2.1 \AA)$ according to the Westlake $\mathrm{H}-\mathrm{H}$ repulsion criteria [10]. Thus, the D2 site occupancy of $0.13(1)$, close to $1 / 6$, is consistent with its deuterium atoms environment. The shortest D-D distance (D1-D2) which is $2.36 \AA$ is comparable to that for $\mathrm{LaNi}_{3} \mathrm{BD}_{2.7}(2.33 \AA)$ [11] and slightly higher than that in $\mathrm{Nd}_{2} \mathrm{Fe}_{14} \mathrm{~B}$ (2.24 ̊) [12].

We can argue that the D1 site is initially occupied because it has the most Nd-rich environment and a much larger size compared to D2. One can also assume that the occupancy of the D1 site is maximum before slightly decreasing when the D2 site start to be filled because both sites share a face.

Thus, it appears that deuterium atoms do not have boron as nearest neighbors since none of the $\left[\mathrm{Nd}_{2} \mathrm{FeB}\right]$ or $\left[\mathrm{Nd}_{2} \mathrm{~B}_{2}\right]$ interstices in the host structure are filled but only octahedral and tetrahedral interstices essentially formed by $\mathrm{Nd}$ atoms. Let's recall that neither elemental iron nor metallic boron absorb a significant amount of hydrogen as described earlier [13] and consequently no hydrogen atom is expected in the close neighborhood of the boron atoms. This observation is in good agreement with earlier reported discussion that B does not accept hydrogen as near neighbor in other Nd-Fe-B ternary intermetallic compounds such as $\mathrm{Nd}_{2} \mathrm{Fe}_{14} \mathrm{~B}$ [12]. In $\mathrm{Nd}_{2} \mathrm{Fe}_{14} \mathrm{BH}_{\mathrm{x}}$ the $\mathrm{H}$ atoms are located firstly in pseudo-tetrahedral sites with three $\mathrm{Nd}$ atoms and one $\mathrm{Fe}$ and then in sites with two $\mathrm{Nd}$ and two $\mathrm{Fe}$ atoms as closest neighbors. Our results also confirm those obtained for other borides such $\mathrm{LaNi}_{3} \mathrm{~B}$ or $R T_{4} \mathrm{~B}$ $[11,14,15]$. For example, in $\mathrm{LaNi}_{3} \mathrm{BD}_{\mathrm{x}}$ deuterium atoms have been found in four interstices formed by $\mathrm{La}$ and $\mathrm{Ni}$ atoms only, i.e. two tetrahedral $\left[\mathrm{La}_{2} \mathrm{Ni}_{2}\right]$, trigonal-prismatic $\left[\mathrm{La}_{3} \mathrm{Ni}_{3}\right]$ and trigonal-bipyramidal $\left[\mathrm{La}_{2} \mathrm{Ni}_{3}\right]$ sites. It confirms the weak interactions between $\mathrm{D}($ or $\mathrm{H})$ and $\mathrm{B}$ atoms.

\subsection{Magnetization and specific heat measurements}


The magnetization measurements performed after zero field cooling (ZFC) and by field cooling (FC) is shown on figure 3 for polycrystalline $\mathrm{Nd}_{5} \mathrm{Fe}_{2} \mathrm{~B}_{6}$ and the deuteride. The magnetization of the intermetallic (Fig. 3-up) displays a sharp ferro-like transition at 64.5(5) $\mathrm{K}$ (inflection point of $\mathrm{M}(\mathrm{T})$ ) and a splitting of the ZFC and FC curves since we observe a continuous increase of FC-M(T) below $\mathrm{T}_{\mathrm{C}}$ and a pronounced diminution of ZFC-M(T) below $40 \mathrm{~K}$ reaching almost zero below $10 \mathrm{~K}$. This behaviour may indicate a strong magnetocrystalline anisotropy or a canted ferromagnetic order. The Curie temperature of the boride, around $68 \mathrm{~K}$, is in fair agreement with all previous results reported on $\mathrm{Nd}_{5} \mathrm{Fe}_{2} \mathrm{~B}_{6}[16$, $3]$.

After deuteration the Curie temperature is significantly reduced to 21(1) K (Fig 3-down). The ZFC and FC curves deviate from each other below $\mathrm{T}_{\mathrm{C}}$ and also present a second anomaly around $8 \mathrm{~K}$. In the insets of the figure 3 , the inverse of the susceptibility is represented for both samples. For $\mathrm{Nd}_{5} \mathrm{Fe}_{2} \mathrm{~B}_{6} \mathrm{D}_{4.1}$ the plot clearly shows a Curie-Weiss behaviour and the linear fit leads to a paramagnetic temperature of $9 \mathrm{~K}$ and an effective moment of $3.63 \mu_{\mathrm{B}}$, i.e. the value expected by the Hund's rule for the trivalent state of $\mathrm{Nd}\left(3.62 \mu_{\mathrm{B}}\right)$ which suggests that no magnetic moment is carried by the $\mathrm{Fe}$ atom. The inverse of the susceptibility of $\mathrm{Nd}_{5} \mathrm{Fe}_{2} \mathrm{~B}_{6}$ exhibits a linear behaviour above $150 \mathrm{~K}$ and a Curie-Weiss fit gives an effective moment of 4.2(1) $\mu_{\mathrm{B}}$ which corresponds to $\mu_{\mathrm{eff}}=3.1 \mu_{\mathrm{B}} / \mathrm{Fe}$ atom considering $\mu_{\mathrm{eff}}=3.62 \mu_{\mathrm{B}}$ for $\mathrm{Nd}^{3+}$. This high value of the effective moment suggests that iron is magnetic in this compound. On the other side, the curve for $\mathrm{Nd}_{5} \mathrm{Fe}_{2} \mathrm{~B}_{6}$ reveals a gradual decrease of the slope with increasing temperature as can be observed for a ferrimagnetic compound or for a sample with a small amount of an impurity. The fit of the data tacking into account an extra contribution $\chi_{0}\left(6.10^{-3}\right.$ $\mathrm{mol} / \mathrm{emu}$ ) in addition of the Curie-Weiss law gives an effective moment of $3.48 \mu_{\mathrm{B}}$ and $\theta_{\mathrm{p}}=$ $56 \mathrm{~K}$.

The effective iron magnetic moment found with the Curie-Weiss fit is large but however smaller than that reported for $\mathrm{ThFe}_{11} \mathrm{C}_{\mathrm{x}}$ and $R_{2} \mathrm{Fe}_{17} \mathrm{C}_{\mathrm{x}}$ type intermetallic compounds [17-19]. Yet, this value is close to the effective magnetic moment of elemental iron, a value of $3.13 \mu_{\mathrm{B}}$ per iron being usually reported for the effective magnetic moment of elemental iron. From the value of $\mu_{\text {eff }}=3.1 \mu_{\mathrm{B}} / \mathrm{Fe}$ atom deduced from the Curie Weiss constant of $\mathrm{Nd}_{5} \mathrm{Fe}_{2} \mathrm{~B}_{6}$ we obtain a number of magnetic carrier of 2.26 per $\mathrm{Fe}$ atom in the paramagnetic state.

It is worth pointing out that the iron effective magnetic moment deduced from the paramagnetic state is much larger than the Fe magnetic moment obtained in the ordered state (see section 2.4). Following the Rhodes-Wolfarth plots [20] such behaviour is indicative of the large itinerant character of the Fe magnetism in $\mathrm{Nd}_{5} \mathrm{Fe}_{2} \mathrm{~B}_{6}$ compound. 
Isothermal magnetization measurements were performed on powder of $\mathrm{Nd}_{5} \mathrm{Fe}_{2} \mathrm{~B}_{6}$ at $1.8,20$ and $45 \mathrm{~K}$ and on $\mathrm{Nd}_{5} \mathrm{Fe}_{2} \mathrm{~B}_{6} \mathrm{D}_{4.1}$ at 1.8 and $15 \mathrm{~K}$ (Figure 4). For $\mathrm{Nd}_{5} \mathrm{Fe}_{2} \mathrm{~B}_{6}$ the $\mathrm{M}\left(\mu_{0} \mathrm{H}\right)$ virgin curves at 20 and $40 \mathrm{~K}$ clearly evidence a ferromagnetic behaviour by a strong rise of $\mathrm{M}$ at low fields and a tendency to the saturation at high fields. However, at $1.8 \mathrm{~K}$, the magnetization rises almost linearly at low field then undergoes a sharp increase around $1.5 \mathrm{~T}$ and tends to saturate at $7 \mathrm{~T}$. This behaviour may suggest a strong pinning of the domain wall in agreement with the ZFC-M(T). An alternative interpretation could be the occurrence of an antiferro- to ferromagnetic metamagnetic transition. However, this hypothesis is ruled out by the neutron diffraction investigation, as will be presented in section 2.4, which reveals a ferromagneticlike ground state. The virgin curves of deuteride clearly suggest a ferromagnetic state but with a lower magnetization at low temperature than the parent boride, namely $10 \mu_{\mathrm{B}} / \mathrm{f}$.u. against $10.8 \mu_{\mathrm{B}} /$ f.u. for $\mathrm{Nd}_{5} \mathrm{Fe}_{2} \mathrm{~B}_{6}$. In a nutshell, the hydrogenation of $\mathrm{Nd}_{5} \mathrm{Fe}_{2} \mathrm{~B}_{6}$ induces a decrease of the Curie temperature and of the magnetic moment of the $\mathrm{Nd}$ atoms.

For further physical characterization we performed specific heat measurements at zero fields which are shown on figure 5 . The $C_{p}(T)$ curve of the boride exhibits a lambda peak at $64 \mathrm{~K}$, in agreement with the magnetization data. On the other hand the curve of the deuteride presents a less pronounced peak at $21 \mathrm{~K}$ and an additional small bump around $8 \mathrm{~K}$ which may corresponds to the second anomaly observed in the magnetization curves.

\subsection{Mössbauer spectroscopy}

${ }^{57} \mathrm{Fe}$ Mössbauer spectra of $\mathrm{Nd}_{5} \mathrm{Fe}_{2} \mathrm{~B}_{6}$ and $\mathrm{Nd}_{5} \mathrm{Fe}_{2} \mathrm{~B}_{6} \mathrm{D}_{4.1}$ were recorded at room temperature (RT) and $4.2 \mathrm{~K}$ (figure 6). All the refined hyperfine parameters are gathered in Table 4.

At room temperature the spectrum of the boride can be described by a single quadrupole doublet characteristic of one crystallographic site for the Fe atoms in the structure, in good agreement with the structural results. Indeed, the Mössbauer spectrum was reconstructed considering an asymmetry of the electric field gradient (EFG) and using the full Hamiltonian method (excited-state spin $I=3 / 2$ and ground-state spin $I=1 / 2$ ), which led to a good fit of the experimental data. At $4.2 \mathrm{~K}$, in addition to the EFG the iron nucleus also experienced a weak magnetic field which may be transferred from $\mathrm{Nd}$ to Fe atoms. The calculated octuplet is then characterized by a non-zero value of the EFG asymmetry parameter $(\eta=0.6)$ and a weak magnetic hyperfine field $\left(\mathrm{B}_{\mathrm{hf}}=2.4 \mathrm{~T}\right)$. Furthermore, Mössbauer spectra of the $\mathrm{Nd}_{5} \mathrm{Fe}_{2} \mathrm{~B}_{6}$ compound were recorded at various temperature from $293 \mathrm{~K}$ down to $4.2 \mathrm{~K}$ (figure $7 \mathrm{a}$ ) and allowed us to follow the variation with temperature of all hyperfine parameters. As the temperature decreases, the isomer shift increases due to the second-order Doppler effect and 
the quadrupole splitting (and asymmetry parameter) remains constant (figure 7b), which confirms that there is only one crystallographic site for Fe. Moreover, the variation of the hyperfine magnetic field with temperature clearly shows that a magnetic ordering occurs between $72.5 \mathrm{~K}$ and $75 \mathrm{~K}$ (figure $7 \mathrm{~b}$ ). These results are consistent with the magnetic susceptibility measurements as well as the neutron diffraction refinements that did not reveal any structural transition at low temperature but show the presence of a small magnetic moment on the Fe site (see section 2.4). All these results corroborate and complete the study of Deppe et al. that suggested that an Nd-Fe exchange induced polarization of conduction electrons might give rise to a hyperfine field at the Fe site [21].

The deuteride sample, $\mathrm{Nd}_{5} \mathrm{Fe}_{2} \mathrm{~B}_{6} \mathrm{D}_{4.1}$, exhibits a quite different Mössbauer signature, revealing that the insertion of deuterium into the boride structure is effective and clearly affects the iron site. At room temperature, the Mössbauer spectrum (figure 6) may be considered as the sum of two quadrupole doublets associated with two different local environments for the Fe atoms. The main component (Fe2, about 75\%) with a low value of the quadrupole splitting $(0.11 \mathrm{~mm} / \mathrm{s}$ at $\mathrm{RT})$ can be related to $\mathrm{Fe}$ atoms located at a crystallographic site with low distortion and with deuterium atoms in its vicinity. The deuteration of the boride $\mathrm{Nd}_{5} \mathrm{Fe}_{2} \mathrm{~B}_{6} \mathrm{D}_{4.1}$ seems to induce some local constraints that have a direct effect on the symmetry of the Fe sites. The second component (Fe1) of the Mössbauer spectrum is associated with a "non-deuterated" site very similar to the Fe site of the starting boride. The Fe1 signal may actually be analysed as the sum of quadrupole doublets with lorentzian shape (linewidth: $0.30 \mathrm{~mm} / \mathrm{s})$, same isomer shift $(0.14 \mathrm{~mm} / \mathrm{s}$ at RT) but different quadrupole splitting values. Such distribution of the quadrupole splitting values (see insets in figure 6) as well as the $\mathrm{Fe} 2$ signal linewidth (>0.35 mm/s) reflects slight variations of the EFG at the $\mathrm{Fe}$ sites due to some local disorder or heterogeneity in site distortion, what could be related to the distribution of deuterium in the $\mathrm{D} 2\left[\mathrm{Nd}_{3} \mathrm{Fe}\right](13 \%)$ and $\mathrm{D} 1\left[\mathrm{Nd}_{6}\right](85 \%)$ sites. At $4.2 \mathrm{~K}$, some changes are observed on the Mössbauer spectrum of $\mathrm{Nd}_{5} \mathrm{Fe}_{2} \mathrm{~B}_{6} \mathrm{D}_{4.1}$ but no magnetic component appears and the relative proportion of the $\mathrm{Fe} 1$ and $\mathrm{Fe} 2$ components is kept. This suggests that no magnetic field is present on the Fe site, which is in agreement with the magnetic measurement in the paramagnetic regime showing only an effective moment resulting from the trivalent $\mathrm{Nd}$ and with the neutron diffraction refinement at $1.8 \mathrm{~K}$.

\subsection{Magnetic structure}


Several neutron diffraction patterns were recorded from the Curie temperature and down to $1.8 \mathrm{~K}$ for both compounds.

In both compounds, magnetic intensities appear below $\mathrm{T}_{\mathrm{C}}$ on the nuclear peaks which indicates that the propagation vector is equal to $\mathbf{k}=\left(\begin{array}{lll}0 & 0 & 0\end{array}\right)$ and that the magnetic cell corresponds to the nuclear unit cell. Also, the intensities of $\left(\begin{array}{lll}0 & 0 & 1\end{array}\right)$ lines are null, suggesting that the direction of the magnetic moments is mainly along the $c$-axis since only the magnetic moment component perpendicular to the scattering vector contributes to the magnetic intensity. For $\mathrm{Nd}_{5} \mathrm{Fe}_{2} \mathrm{~B}_{6}$ the best refinement is indeed obtained with a ferromagnetic structure with moments parallel to $c$ (Figure 8). The values of the magnetic moments amount to $\mu_{1}=$ 2.36(8) $\mu_{\mathrm{B}}, \mu_{2}=2.71(6) \mu_{\mathrm{B}}, \mu_{3}=2.87(5) \mu_{\mathrm{B}}$ for $\mathrm{Nd} 1, \mathrm{Nd} 2$ and $\mathrm{Nd} 3$ respectively and a small moment of $0.8(2) \mu_{B}$ is found on the Fe site. Note that our attempts to refine the magnetic structure without contribution of the $\mathrm{Fe}$ site, with a canted ferromagnetic structure for example, yielded less good refinements with significant higher agreement factors. Likewise, the same ferromagnetic structure was found for the deuteride except that no significant magnetic moment was found on the Fe atom (Figure 9). Also, the magnetic moments values are weaker for $\mathrm{Nd}_{5} \mathrm{Fe}_{2} \mathrm{~B}_{6} \mathrm{D}_{4.1}$ since they are refined to $\mu_{1}=1.92(8) \mu_{\mathrm{B}}, \mu_{2}=1.47(5) \mu_{\mathrm{B}}, \mu_{3}=$ 1.56(5) $\mu_{\mathrm{B}}$ for $\mathrm{Nd} 1, \mathrm{Nd} 2$ and $\mathrm{Nd} 3$ respectively. The thermal evolution of the magnetic moments is shown on figure 10 for both compounds. Concerning the deuteride, no clear change in the magnetic structure, such as spin reorientation for example, is visible around $8 \mathrm{~K}$ as suggested by the thermomagnetic measurement. However, whereas $\mu_{2}$ and $\mu_{3}$ increase normally in the whole temperature range, $\mathrm{Nd} 1$ tends to saturate rapidly below $\mathrm{T}_{\mathrm{C}}$ and to increase again below $10 \mathrm{~K}$. This could explain the second small anomaly observed on the ZFC-FC curve around $8 \mathrm{~K}$. For $\mathrm{Nd}_{5} \mathrm{Fe}_{2} \mathrm{~B}_{6}, \mu 1$ also saturates rapidly below $\mathrm{T}_{\mathrm{C}}$ but the value stays almost constant when decreasing temperature down to $1.8 \mathrm{~K}$ contrary to $\mu_{2}$ and $\mu_{3}$ which continue to increase. Eventually, $\mu 1$ is significantly higher than $\mu_{2}$ and $\mu_{3}$ in the deuteride and inversely in the non-deuterated compound, meaning that $\mu 1$ is much less reduced than $\mu_{2}$ and $\mu_{3}$ with hydrogen uptake. This may be related to distance $\mathrm{d}(\mathrm{D} 1-\mathrm{Nd} 1)=2.72 \AA$ which is much larger than $\mathrm{d}(\mathrm{D} 1-\mathrm{Nd} 2)=2.64 \AA$ and $\mathrm{d}(\mathrm{D} 1-\mathrm{Nd} 3)=2.62 \AA$, so that the magnetic moment of $\mathrm{Nd} 1$ is less hampered by the presence of the deuterium in its neighborhood.

The magnetic moment of iron atoms is known to be very sensitive to its local atomic environment, in particular to the presence of metalloid as next near neighbor [22]. The proximity of $\mathrm{B}$ atoms in the $\mathrm{Nd}_{5} \mathrm{Fe}_{2} \mathrm{~B}_{6}$ crystal structure is clear from the interatomic distances listed in Table 2. According to the considerations discussed in details elsewhere [22] one can expect a rather low magnetic moment on the $\mathrm{Fe}$ atoms in $\mathrm{Nd}_{5} \mathrm{Fe}_{2} \mathrm{~B}_{6}$. This is indeed what is 
observed since value of $0.8 \mu_{\mathrm{B}}$ is derived from neutron diffraction results. In the $\mathrm{Nd}_{5} \mathrm{Fe}_{2} \mathrm{~B}_{6}$ crystal structure, the Fe atoms neighborhood is both $\mathrm{Nd}$ and $\mathrm{B}$ rich. Altogether such local atomic environment favors a reduction of the $\mathrm{Fe}$ magnetic moment due to electronic hybridization with the $\mathrm{Fe} 3 \mathrm{~d}$ orbitals. This effect has been observed in different R-Fe-B ternary compounds for instance, in $\mathrm{Nd}_{2} \mathrm{Fe}_{14} \mathrm{~B}$ the $\mathrm{Fe}$ atoms have at most two $\mathrm{B}$ as near neighbors [12]. In the $\mathrm{RFe}_{4-\mathrm{x}} \mathrm{Co}_{\mathrm{x}} \mathrm{B}$ type compounds the boron richest Fe environment also present only two B near neighbors [23] leading to reduced Fe magnetic moment of about 1.2 $\mu_{\mathrm{B}}$. This effect is expected to be significantly stronger for $\mathrm{Nd}_{5} \mathrm{Fe}_{2} \mathrm{~B}_{6}$ compound since its peculiar crystal structure exhibits a large number of Fe near neighbors: $6 \mathrm{~B}$ atoms with $\mathrm{d}(\mathrm{Fe}-$ B) $=2.17 \AA$. In addition, a calculation of the Wigner-Seitz atomic cell [24] around the $\mathrm{Fe}$ position give a moderate value of $11.6 \AA^{3}$ assuming the following radii $1.82,1.26$ and $0.92 \AA$ for $\mathrm{Nd}, \mathrm{Fe}$ and $\mathrm{B}$ respectively. As discussed elsewhere, such reduced value does not favor large Fe magnetic moment either [22].

It is worth to point out that $\mathrm{Fe}$ is found to order at the same temperature as the $\mathrm{Nd}$ sublattice, which is a remarkably low magnetic ordering temperature for Fe containing intermetallic compound. The fact that the Fe sublattice does not order independently or at least at higher temperature is indicative of the low Fe-Fe exchange interactions. This can be understood in the light of the crystal structure which does not present direct Fe-Fe bonds. The closest Fe-Fe interatomic distances are at $3.95 \AA$ that is much larger than the sum of the metallic Fe radii $(2 * 1.27 \AA)$. Such large Fe-Fe interatomic distances most probably preclude the independent magnetic ordering of the iron sublattice. On the contrary the short $\mathrm{Nd}-\mathrm{Nd}$ interatomic distances are expected to play a crucial role in the establishment of the magnetic ordering, an ordering that is transferred to the $\mathrm{Fe}$ atoms via direct and strong $\mathrm{Nd}-\mathrm{Fe}$ bonds as witnessed by the short $\mathrm{Nd}-\mathrm{Fe}$ interatomic distances observed in the $\mathrm{Nd}_{5} \mathrm{Fe}_{2} \mathrm{~B}_{6}$ compound. Consequently $\mathrm{Nd}_{5} \mathrm{Fe}_{2} \mathrm{~B}_{6}$ exhibits an unusual feature: unlike other $R$-Fe binary or ternary intermetallic compounds whose ordering temperature is dominated by Fe-Fe exchange interactions (direct $3 \mathrm{~d}-3 \mathrm{~d}$ one), the Curie temperature of $\mathrm{Nd}_{5} \mathrm{Fe}_{2} \mathrm{~B}_{6}$ compound is dominated by indirect $\mathrm{Nd}-\mathrm{Nd}$ (of RKKY type) as well as indirect Nd-Fe between the 4f inner shell of $\mathrm{Nd}$ and the $3 \mathrm{~d}$ of $\mathrm{Fe}$ mediated by the $5 \mathrm{~d}$ electrons.

It appears that deuteration of $\mathrm{Nd}_{5} \mathrm{Fe}_{2} \mathrm{~B}_{6}$ prevents a magnetic moment from being induced on the $\mathrm{Fe}$ atom or it is too small to be measured with neutron diffraction data. This can be accounted for by the diminution of the magnetic moment carried by the neodymium atoms and the increase of the Nd-Fe distances, especially the shortest one Nd1-Fe. Those results are 
in fair agreement with the magnetic measurement. Last but not least the presence of many D atoms inserted in the local Fe environment maybe detrimental for the Fe magnetic moment as it has been reported for $\mathrm{YFe}_{2} \mathrm{D}_{\mathrm{x}}$ compounds $[25,26]$. It was shown by both experimental studies and theoretical calculations that there is no magnetic order for the $\mathrm{YFe}_{2} \mathrm{H}_{5}$ hydride. In $\mathrm{Nd}_{5} \mathrm{Fe}_{2} \mathrm{~B}_{6}$ this occurs via the filling of the $\mathrm{D} 2$ position that is the closest to the Fe site.

\section{Conclusion}

In this paper, the structural and the magnetic properties of the $\mathrm{Nd}_{5} \mathrm{Fe}_{2} \mathrm{~B}_{6}$ and $\mathrm{Nd}_{5} \mathrm{Fe}_{2} \mathrm{~B}_{6} \mathrm{D}_{4.1}$ compounds have been studied by means of magnetization measurements, specific heat, Mössbauer spectroscopy and neutron diffraction, in order to highlight the influence of H/D insertion in the boride on the magnetic behavior.

The $\mathrm{Nd}_{5} \mathrm{Fe}_{2} \mathrm{~B}_{6}$ compound exhibits a magnetic ordering below about $68 \mathrm{~K}$. Powder neutron diffraction investigations have evidenced a ferromagnetic structure with $\mathrm{Nd}$ and $\mathrm{Fe}$ magnetic moments along the $c$-axis. Complementary ${ }^{57} \mathrm{Fe}$ Mössbauer spectroscopy has been undertaken confirming the existence of a small ordered magnetic moment on iron. The thermal dependence of the hyperfine parameters has been reported between 4.2 and 100K. The Curie temperature corresponds to a remarkably low magnetic ordering temperature for $\mathrm{Fe}$ containing intermetallic compound. Both $\mathrm{Fe}$ and $\mathrm{Nd}$ atoms are found to carry a magnetic moment and $\mathrm{Fe}$ atom is found to order at the same time as the $\mathrm{Nd}$ sublattice. This may originate from the low magnetic moment carried by the Fe atoms in the ordered state as well as the non direct $\mathrm{Fe}-\mathrm{Fe}$ exchange interactions due to long Fe-Fe interatomic distances thus hampering the ordering of the Fe sublattice independently from the $\mathrm{Nd}$ one. Indeed a value of about $0.8 \mu_{\mathrm{B}} / \mathrm{Fe}$ has been determined from the neutron diffraction investigation a value much smaller than the $2.2 \mu_{\mathrm{B}}$ typical of elemental iron. Such low magnetic moment on the Fe atoms has been attributed to the proximity of boron and the large rare-earth content in the $\mathrm{Nd}_{5} \mathrm{Fe}_{2} \mathrm{~B}_{6}$ compound. Analyzing the magnetic properties in both the paramagnetic and ordered state in the frame of the Rhodes-Wolfarth model reveals that in $\mathrm{Nd}_{5} \mathrm{Fe}_{2} \mathrm{~B}_{6}$ the $\mathrm{Fe} 3 \mathrm{~d}$ magnetism is significantly more delocalized when compared to alpha-Fe.

According to magnetic measurements, specific heat and neutron diffraction investigation, the $\mathrm{Nd}_{5} \mathrm{Fe}_{2} \mathrm{~B}_{6} \mathrm{D}_{4.1}$ deuteride exhibits a much lower ordering temperature of about $21 \mathrm{~K}$ as a consequence of $\mathrm{D}$ insertion in the $\mathrm{Nd}$ environment. $\mathrm{D}$ atoms are accommodated in two 
inequivalent interstitial sites: one pseudo octahedral D1 [Nd6] and one pseudo tetrahedral D2 [Nd3Fe], both avoiding B as near neighbor. This insertion induces a pronounced anisotropic unit cell expansion along the $c$-axis. The magnetic structure remains ferromagnetic with magnetic moments parallel to the $c$-axis but with reduced values compared to those of the initial boride. Deuterium / hydrogen insertion leads to the destruction of the Fe magnetic moment, which vanishes in the $\mathrm{Nd}_{5} \mathrm{Fe}_{2} \mathrm{~B}_{6} \mathrm{D}_{4.1}$ compound as evidenced by neutron diffraction experiments and Mössbauer spectroscopy. This most probably arises from electronic effect of D insertion that contributes to partial filling of the $3 \mathrm{~d}$ electronic band together with the presence of several $\mathrm{Nd}$ atoms as near neighbors. Further electronic calculation would be interesting to validate this interpretation.

\section{References}

[1] O. M. Dub, N. F. Chaban and Y. B. Kuz'ma, J. Less-Common Met. 117 (1986) 297.

[2] S. O. Yuryev, S. I. Yushchuk, Y. B. Kuz'ma, I. E. Lopatsynsky, J. Alloys Comp. 270 (1998) 16.

[3] V. A. Yartys, A. I. Shtogrin, and M. I. Bartashevich, Koord. Khim. 18(4) (1992) 436.

[4] V. A. Yartys, G. Wiesinger, I. R. Harris, J. Alloys Comp. 252 (1997) 201.

[5] V. A. Yartys, O. Gutfleisch, I. R. Harris, J. Alloys Comp. 253 (1997) 134.

[6] V. A. Yartys, R. V. Denys, O. Gutfleisch, I. I. Bulyk, Y. B. Kuz'ma, I. R. Harris, Int. J. Hydr. En. 24 (1999) 189.

[7] V. V. Panasyuk and V. A. Yartys, Z. Phys. Chem. 179 (1993) 479.

[8] P. Dalmas De Reotier, D. Fruchart, P. Wolfers, P. Vulliet, A. Yaouanc, R. Fruchart, P. L'heritier, Journal de Physique Colloques 46(C6) (1985) C6-249.

[9] J. Rodriguez-Carvajal, Physica B 192 (1993) 55.

[10] D. G. Westlake, J. Less-Common. Met. 75 (1980) 177.

[11] Y. E. Filinchuk and K. Yvon, Inorg. Chem. 44 (2005) 4398.

[12] O. Isnard, W. B. Yelon, S. Miraglia, and D. Fruchart, J. Appl. Phys. 78 (1995) 1892.

[13] S. Rundquist, R. Tellgreen, Y. Andersson, J. Less-Comm. Met. 101 (1984) 145-168. 
[14] F.E. Spada, H. Oesterreicher, R.C. Bowman, M.P. Guse, Phys. Rev. B 30 (1984) 49094924.

[15] F. Spada, H. Oesterreicher, J. Less-Comm. Met. 90 (1983) L1-L4.

[16] K. H. J. Buschow, D. B. De Mooij, J. L. C. Daams and H. M. Van Noort, J. LessCommon Met. 115 (1986) 357.

[17] O. Isnard, V. Pop, K.H.J. Buschow J. Magn. Magn. Mat. 256 (2003) 133.

[18] E. Burzo, F. Givord, C.R.Acad.Sc. Paris 271 (1970) 1159-1161.

[19] O. Isnard, V. Pop, K.H.J. Buschow, J. Appl. Phys. 101 (2007) 103908-103908.

[20] P.R. Rhodes, E.P. Wolfarth, Proc. R. Soc. 273 (1963) 347.

[21] P. Deppe and M. Rosenberg, Solid State Comm. 64 (1987) 1247.

[22] O. Isnard, D. Fruchart, J. Alloys Comp. 205 (1994) 1.

[23] C.Chacon, O. Isnard, J. Appl. Phys. 89 (2001) 71-75.

[24] L. Gelato, Journal of Appl. Cryst. 14 (1981) 151-153.

[25] V. Paul-Boncour, S. M. Filipek, A. Percheron-Guegan, I. Marchuk, and J. Pielaszek, J. Alloys Compd. 317-318 (2001) 83-87.

[26] V. Paul-Boncour, S. Matar, Phys. Rev. B 70 (2004) 184435. 
Table 1. Crystal structure parameters for $\mathrm{Nd}_{5} \mathrm{Fe}_{2} \mathrm{~B}_{6}$ and $\mathrm{Nd}_{5} \mathrm{Fe}_{2} \mathrm{~B}_{6} \mathrm{D}_{4.1(2)}$ at $100 \mathrm{~K}$. Standard deviation are given in parenthesis.

\begin{tabular}{llllll}
\hline Position & Wyck. & $x$ & $y$ & $z$ & Occ \\
\hline $\mathrm{Nd} 1$ & $3 a$ & 0 & 0 & 0 & 1 \\
$\mathrm{Nd} 2$ & $6 c$ & 0 & 0 & $0.2498(2)$ & 1 \\
$\mathrm{Nd} 3$ & $6 c$ & 0 & 0 & $0.4181(2)$ & 1 \\
$\mathrm{Fe}$ & $6 c$ & 0 & 0 & $0.1171(2)$ & 1 \\
$\mathrm{~B}$ & $18 g$ & 0.332 & 0 & 0.5 & 1 \\
\hline $\mathrm{a}=5.4430(4) \AA$ & $\mathrm{c}=24.133(3) \AA$ & & & \\
\hline
\end{tabular}

\begin{tabular}{llllll}
\hline Position & Wyck. & $x$ & $y$ & $z$ & Occ \\
\hline $\mathrm{Nd} 1$ & $3 a$ & 0 & 0 & 0 & 1 \\
$\mathrm{Nd} 2$ & $6 c$ & 0 & 0 & $0.2476(2)$ & 1 \\
$\mathrm{Nd} 3$ & $6 c$ & 0 & 0 & $0.4178(2)$ & 1 \\
$\mathrm{Fe}$ & $6 c$ & 0 & 0 & $0.1170(1)$ & 1 \\
$\mathrm{~B}$ & $18 g$ & 0.332 & 0 & 0.5 & 1 \\
$\mathrm{D} 1$ & $9 e$ & 0.5 & 0 & 0 & $0.85(1)$ \\
$\mathrm{D} 2$ & $36 i$ & $0.203(2)$ & $0.026(4)$ & $0.0664(6)$ & $0.13(1)$ \\
\hline $\mathrm{a}=5.4463(2) \AA$ & $\mathrm{c}=24.813(2) \AA$ & & & \\
\hline
\end{tabular}

Table 2. Interatomic distances around the $\mathrm{Nd}$ and the $\mathrm{Fe}$ atoms (in $\AA$ ) for the $\mathrm{Nd}_{5} \mathrm{Fe}_{2} \mathrm{~B}_{6}$ and $\mathrm{Nd}_{5} \mathrm{Fe}_{2} \mathrm{~B}_{6} \mathrm{D}_{4.1(2)}$ compounds.

\begin{tabular}{|c|c|c|c|c|c|c|c|}
\hline \multicolumn{2}{|c|}{ distances } & \multirow{2}{*}{$\begin{array}{l}\mathbf{N d}_{\mathbf{5}} \mathbf{F e}_{\mathbf{2}} \mathbf{B}_{\mathbf{6}} \\
2.826(5)\end{array}$} & \multirow{2}{*}{$\begin{array}{c}\mathbf{N d}_{\mathbf{5}} \mathbf{F e}_{\mathbf{2}} \mathbf{B}_{\mathbf{6}} \mathbf{D}_{\mathbf{4 . 1}} \\
2.903(3)\end{array}$} & \multicolumn{2}{|c|}{ distances } & \multirow{2}{*}{$\begin{array}{l}\mathbf{N d}_{\mathbf{5}} \mathbf{F e}_{\mathbf{2}} \mathbf{B}_{\mathbf{6}} \\
3.750(3)\end{array}$} & \multirow{2}{*}{$\begin{array}{c}\mathbf{N d}_{\mathbf{5}} \mathbf{F e}_{\mathbf{2}} \mathbf{B}_{\mathbf{6}} \mathbf{D}_{\mathbf{4 . 1}} \\
3.779(3)\end{array}$} \\
\hline Nd1- & $\mathrm{Fe} \times 2$ & & & Nd3- & $\mathrm{Nd} 1 \times 3$ & & \\
\hline & $\mathrm{Nd} 2 \times 6$ & $3.734(3)$ & $3.796(3)$ & & $\mathrm{Nd} 3 \times 1$ & $3.953(7)$ & $4.079(7)$ \\
\hline & $\mathrm{Nd} 3 \times 6$ & $3.750(3)$ & $3.779(3)$ & & $\mathrm{Nd} 2 \times 1$ & $4.062(7)$ & $4.223(7)$ \\
\hline & $\mathrm{B} \times 12$ & $4.4124(5)$ & $4.5164(3)$ & & $\mathrm{B} \times 6$ & $4.132(2)$ & $4.165(2)$ \\
\hline \multirow[t]{7}{*}{ Nd2- } & $\mathrm{B} \times 6$ & $2.705(4)$ & $2.7071(4)$ & & & & \\
\hline & $\mathrm{Nd} 3 \times 3$ & $3.1427(2)$ & $3.1446(1)$ & Fe- & $\mathrm{D} 2 \times 6$ & - & $1.63(2)$ \\
\hline & $\mathrm{Fe} \times 1$ & $3.202(7)$ & $3.239(1)$ & & $\mathrm{B} \times 6$ & $2.173(3)$ & $2.194(2)$ \\
\hline & $\mathrm{Fe} \times 3$ & $3.245(2)$ & $3.241(6)$ & & $\mathrm{Nd} 1 \times 1$ & $2.826(5)$ & $2.903(3)$ \\
\hline & $\mathrm{Nd} 1 \times 3$ & $3.734(3)$ & $3.796(3)$ & & $\mathrm{Nd} 2 \times 3$ & $3.202(7)$ & $3.239(1)$ \\
\hline & $\mathrm{Nd} 3 \times 1$ & $4.062(7)$ & $4.223(7)$ & & $\mathrm{Nd} 2 \times 1$ & $3.245(2)$ & $3.241(6)$ \\
\hline & $\mathrm{B} \times 6$ & $4.146(2)$ & $4.149(2)$ & & $\mathrm{Nd} 3 \times 3$ & $3.238(2)$ & $3.246(2)$ \\
\hline \multirow[t]{3}{*}{ Nd3- } & $\mathrm{B} \times 6$ & $2.683(4)$ & $2.731(4)$ & & $\mathrm{B} \times 6$ & $3.821(2)$ & $3.834(1)$ \\
\hline & $\mathrm{Nd} 2 \times 3$ & $3.1427(2)$ & $3.1446(1)$ & & D $1 \times 6$ & - & $3.980(2)$ \\
\hline & $\mathrm{Fe} \times 3$ & $3.238(2)$ & $3.246(1)$ & & $\mathrm{Fe} \times 3$ & $3.950(4)$ & $3.995(2)$ \\
\hline
\end{tabular}


Table 3. Selected D-D and D-metal distances (in $\AA$ ) in $\mathrm{Nd}_{5} \mathrm{Fe}_{2} \mathrm{~B}_{6} \mathrm{D}_{4.1}$.

\begin{tabular}{llllll}
\hline D1- & $\mathrm{D} 1 \times 4$ & $2.7232(1)$ & $\mathrm{D} 1-$ & $\mathrm{Nd} 1 \times 2$ & $2.7232(1)$ \\
& $\mathrm{D} 2 \times 4$ & $2.36(1)$ & & $\mathrm{Nd} 2 \times 2$ & $2.645(4)$ \\
& $\mathrm{D} 2 \times 4$ & $2.80(1)$ & & $\mathrm{Nd} 3 \times 2$ & $2.620(4)$ \\
D2- & $\mathrm{D} 2 \times 1$ & $0.82(3)$ & $\mathrm{D2}-$ & $\mathrm{Nd} 1 \times 1$ & $1.95(1)$ \\
& $\mathrm{D} 2 \times 1$ & $1.25(2)$ & & $\mathrm{Nd} 2 \times 1$ & $2.28(1)$ \\
& $\mathrm{D} 2 \times 2$ & $1.80(3)$ & & $\mathrm{Nd} 3 \times 1$ & $2.43(2)$ \\
& $\mathrm{D} 2 \times 1$ & $2.07(2)$ & & $\mathrm{Fe} \times 1$ & $1.63(2)$ \\
& $\mathrm{D} 1 \times 4$ & $2.36(2)$ & & & \\
& $\mathrm{D} 1 \times 4$ & $2.80(2)$ & & & \\
\hline
\end{tabular}

Table 4. ${ }^{57} \mathrm{Fe}$ Mössbauer hyperfine parameters for the $\mathrm{Nd}_{5} \mathrm{Fe}_{2} \mathrm{~B}_{6}$ and $\mathrm{Nd}_{5} \mathrm{Fe}_{2} \mathrm{~B}_{6} \mathrm{D}_{4.1}$ compounds. $\delta$ : isomer shift, $\Delta$ : quadrupole splitting, $\eta$ : asymmetry parameter of the EFG $\eta \equiv\left(V_{\mathrm{xx}}-V_{\mathrm{yy}}\right) / V_{\mathrm{zz}}, \mathrm{B}_{\mathrm{hf}}$ : hyperfine magnetic field, $\Gamma$ : Lorentzian linewidth. *mean value of quadrupole splitting distribution.

\begin{tabular}{|c|c|c|c|c|c|c|c|}
\hline & & $\begin{array}{l}\delta \\
(\mathrm{mm} / \mathrm{s})\end{array}$ & $\begin{array}{l}\Delta \\
(\mathrm{mm} / \mathrm{s})\end{array}$ & $\eta$ & $\begin{array}{l}\mathrm{B}_{\mathrm{hf}} \\
(\mathrm{T})\end{array}$ & $\begin{array}{l}\Gamma \\
(\mathrm{mm} / \mathrm{s})\end{array}$ & $\begin{array}{l}\text { rel. area } \\
(\%)\end{array}$ \\
\hline \multicolumn{8}{|c|}{$\mathrm{Nd}_{5} \mathrm{Fe}_{2} \mathrm{~B}_{6}$} \\
\hline $293 \mathrm{~K}$ & & $0.20(1)$ & $0.70(2)$ & $0.6(1)$ & - & $0.43(2)$ & 100 \\
\hline $4.2 \mathrm{~K}$ & & $0.35(1)$ & $0.74(3)$ & $0.6(1)$ & $2.4(1)$ & $0.33(2)$ & 100 \\
\hline \multicolumn{8}{|c|}{$\mathrm{Nd}_{5} \mathrm{Fe}_{2} \mathrm{~B}_{6} \mathrm{D}_{4.1}$} \\
\hline \multirow[t]{2}{*}{$293 \mathrm{~K}$} & Fe1 & $0.14(1)$ & $0.64 *$ & - & - & $0.30(-)$ & $27(2)$ \\
\hline & $\mathrm{Fe} 2$ & $0.22(1)$ & $0.11(2)$ & - & - & $0.36(2)$ & $73(2)$ \\
\hline \multirow[t]{2}{*}{$4.2 \mathrm{~K}$} & $\mathrm{Fe} 1$ & $0.30(2)$ & $0.69 *$ & - & - & $0.30(-)$ & $25(3)$ \\
\hline & $\mathrm{Fe} 2$ & $0.38(3)$ & $0.24(5)$ & - & - & $0.34(2)$ & $75(3)$ \\
\hline
\end{tabular}



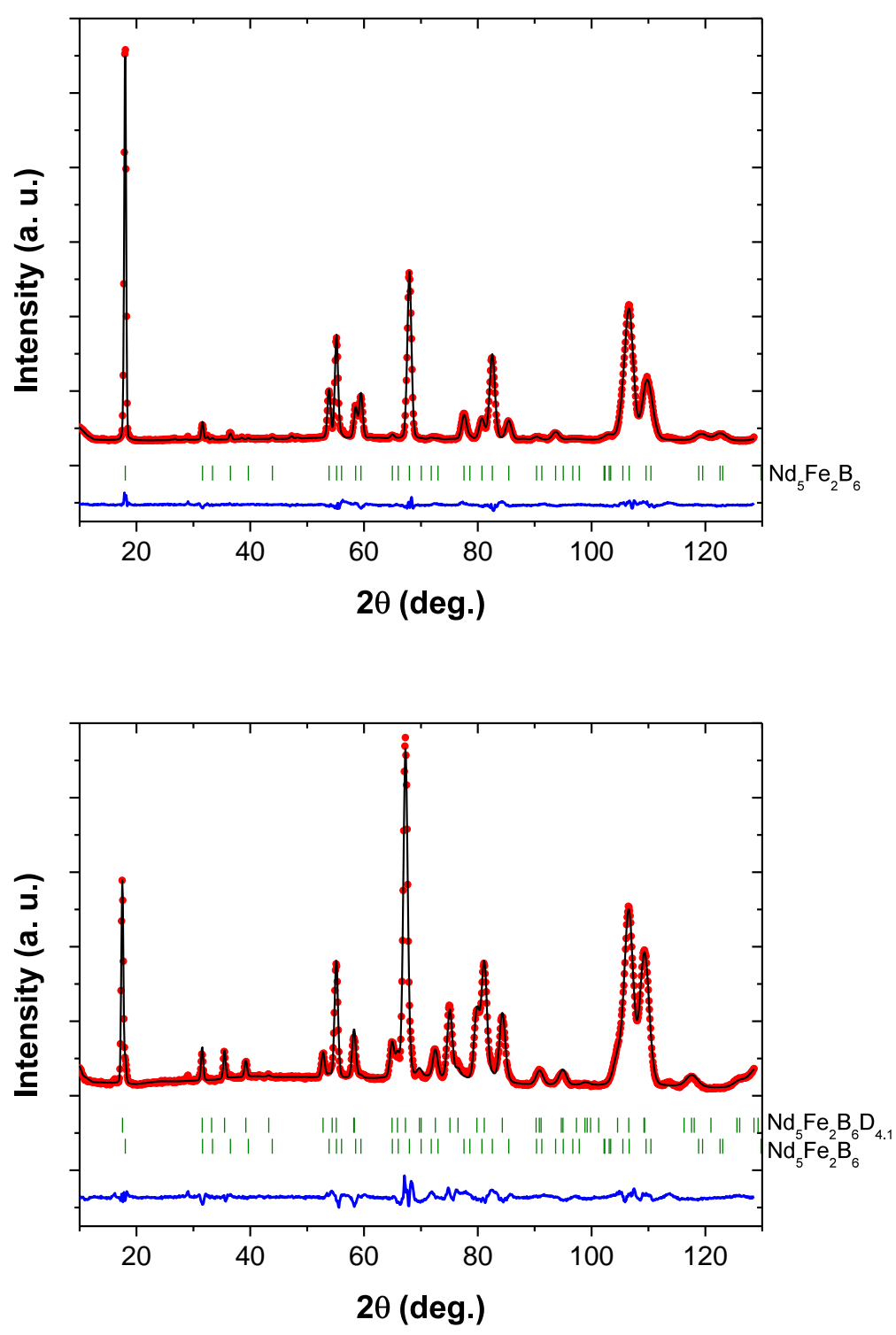

Figure 1. Refinement of the neutron diffraction pattern of $\mathrm{Nd}_{5} \mathrm{Fe}_{2} \mathrm{~B}_{6}$ (up) $\left(\mathrm{R}_{\mathrm{B}}=4.0 \%\right.$, $\left.\mathrm{R}_{\mathrm{wp}}=10.7 \%\right)$ and $\mathrm{Nd}_{5} \mathrm{Fe}_{2} \mathrm{~B}_{6} \mathrm{D}_{4.1}$ (down) $\left(\mathrm{R}_{\mathrm{B}}=3.7 \%, \mathrm{R}_{\mathrm{wp}}=10.7 \%\right)$ recorded at $100 \mathrm{~K}$. A small quantity (4 wt. \%) of the initial boride is still present in the deuterated sample. 

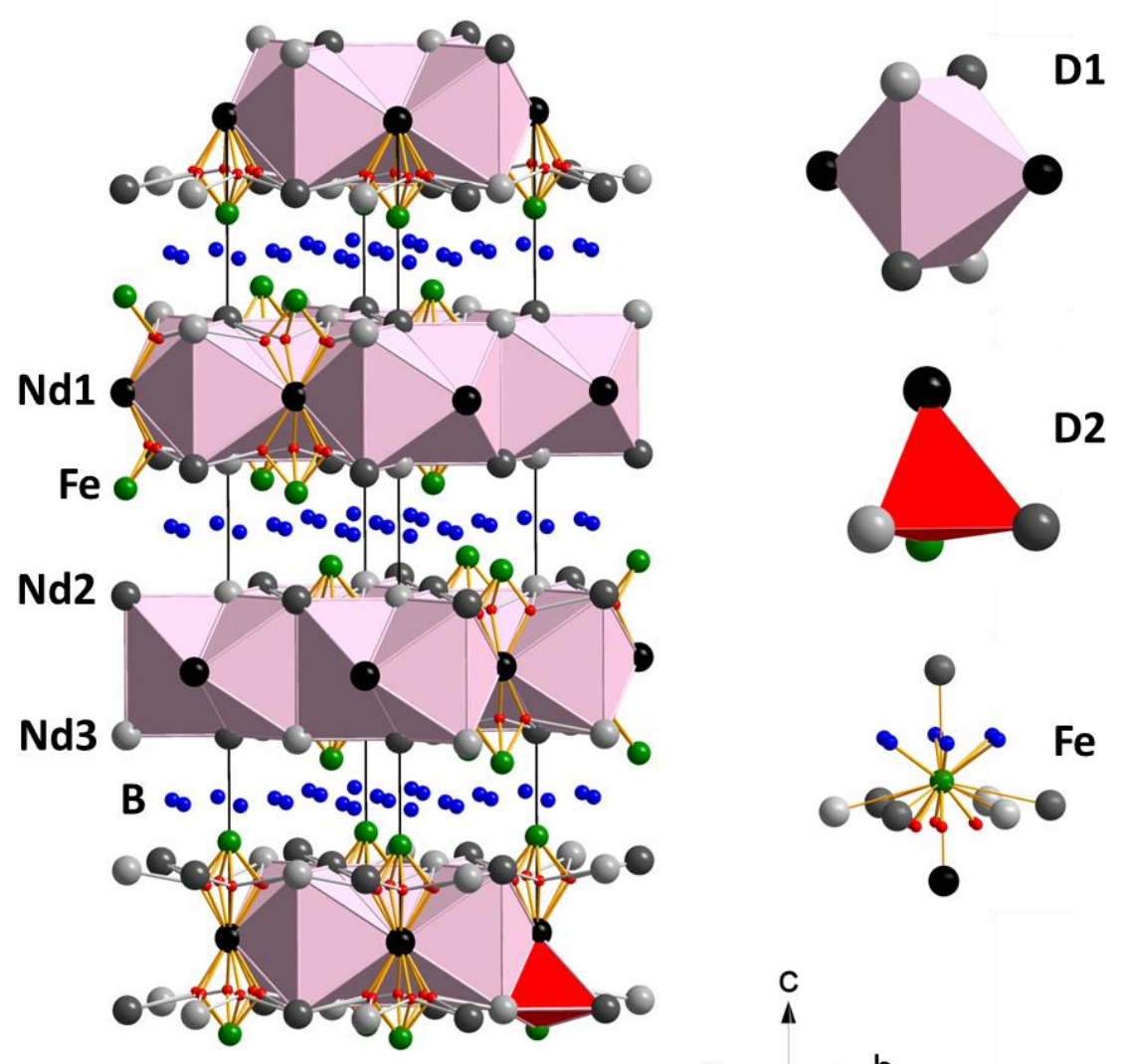

D2

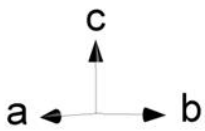

Figure 2: Left: Crystal structure of $\mathrm{Nd}_{5} \mathrm{Fe}_{2} \mathrm{~B}_{6} \mathrm{D}_{4.1}$ emphasizing the D2-metal bonds and the network of $\left[\mathrm{Nd}_{6}\right]$ octahedra containing deuterium atoms D1. Only one $\left[\mathrm{Nd}_{3} \mathrm{Fe}\right]$ tetrahedron containing D2 atom is shown for more clarity. Nd, Fe, B and D2 atoms are represented in grayscale, green, blue and red balls, respectively. Right: $\left[\mathrm{Nd}_{6}\right]$ octahedron and $\left[\mathrm{Nd}_{3} \mathrm{Fe}\right]$ tetrahedron containing D1 and D2 atoms, respectively, and coordination of the iron atoms. 

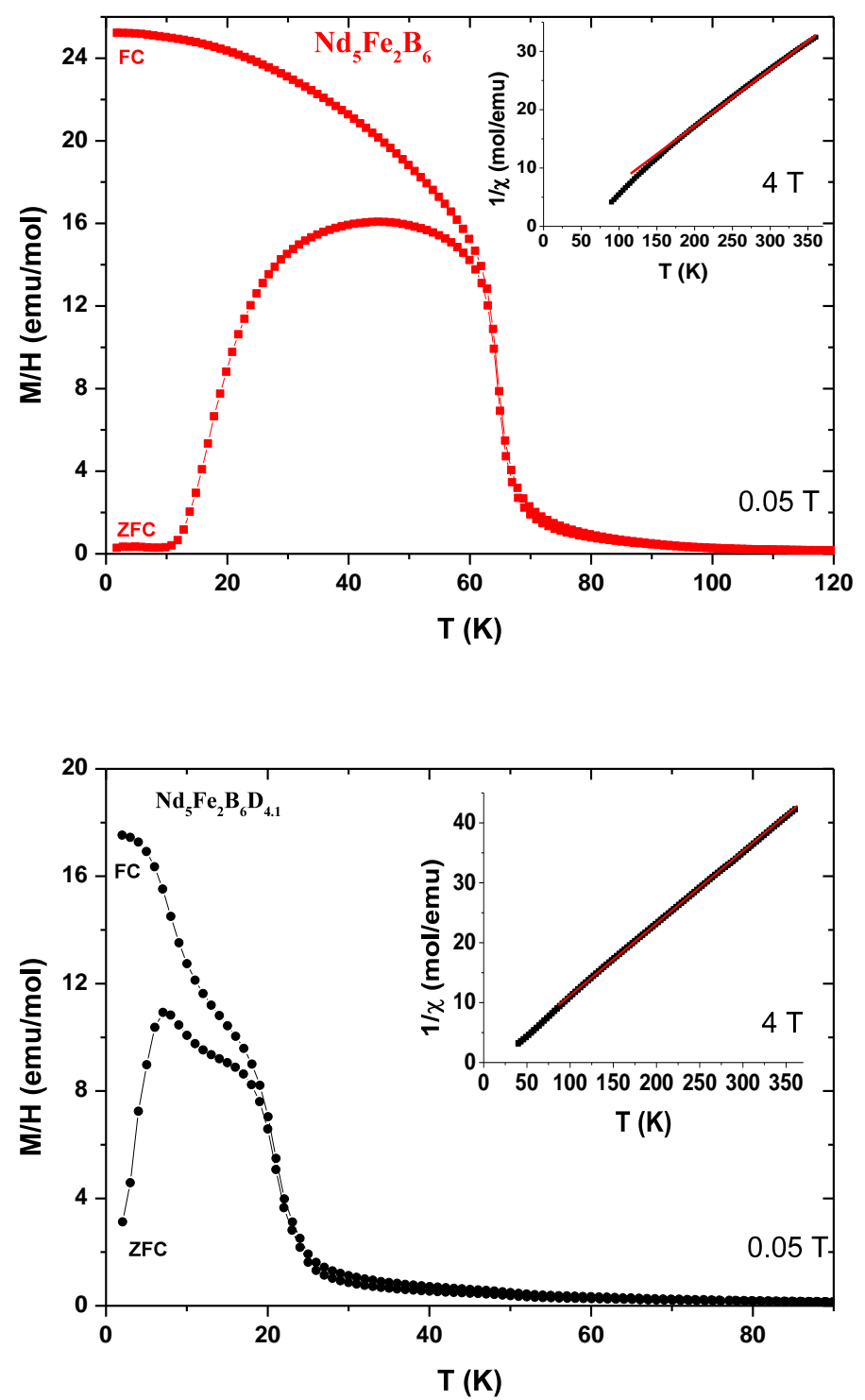

Figure 3. Thermomagnetic measurements of $\mathrm{Nd}_{5} \mathrm{Fe}_{2} \mathrm{~B}_{6}$ (up) and $\mathrm{Nd}_{5} \mathrm{Fe}_{2} \mathrm{~B}_{6} \mathrm{D}_{4.1}$ (down) collected in zero-field-cooled (ZFC) and field-cooled (FC) modes. The insets present the inverse of the susceptibility $v s$ temperature in the paramagnetic regime at $\mu_{0} \mathrm{H}=4 \mathrm{~T}$ with the Curie-Weiss fit. 


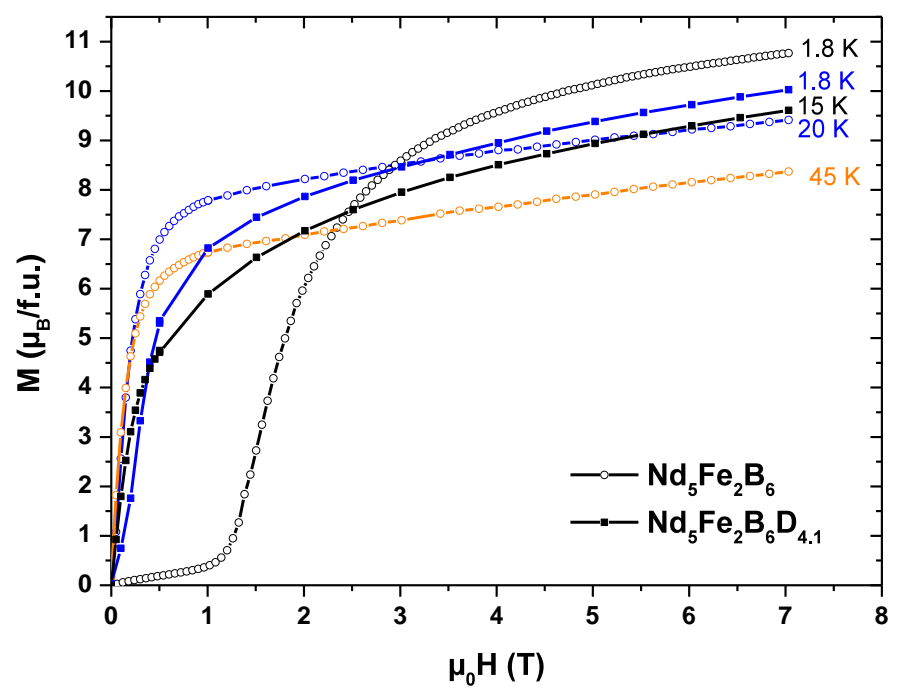

Figure 4. Field dependence of the magnetization of $\mathrm{Nd}_{5} \mathrm{Fe}_{2} \mathrm{~B}_{6}$ (open symbols) and $\mathrm{Nd}_{5} \mathrm{Fe}_{2} \mathrm{~B}_{6} \mathrm{D}_{4.1}$ (close symbols) for several temperatures.

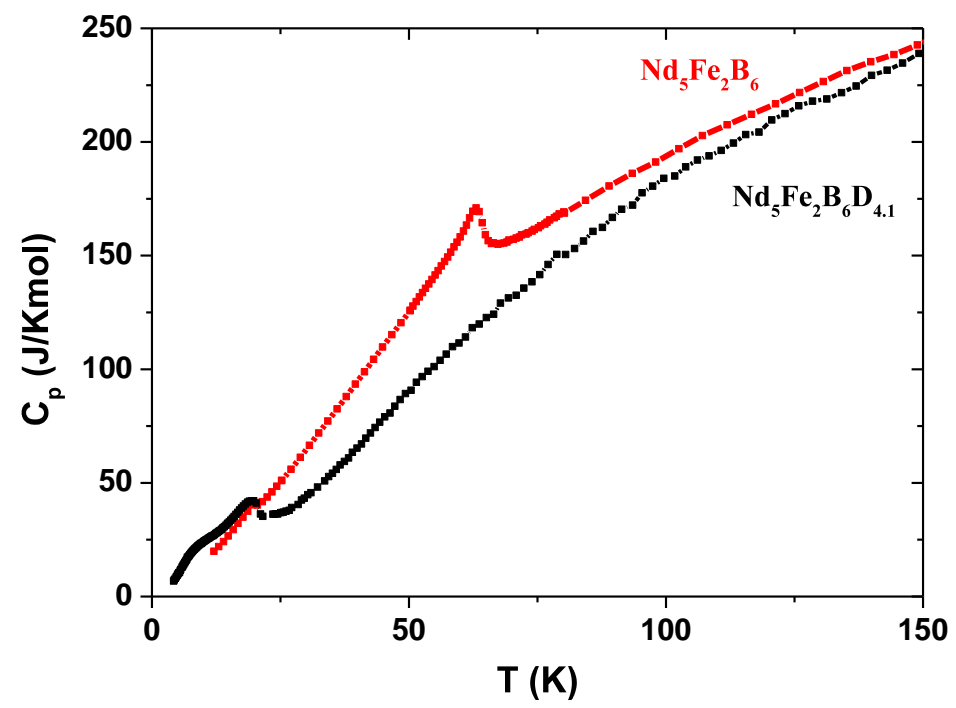

Figure 5. Specific heat measurements performed on $\mathrm{Nd}_{5} \mathrm{Fe}_{2} \mathrm{~B}_{6}$ and $\mathrm{Nd}_{5} \mathrm{Fe}_{2} \mathrm{~B}_{6} \mathrm{D}_{4.1}$. 


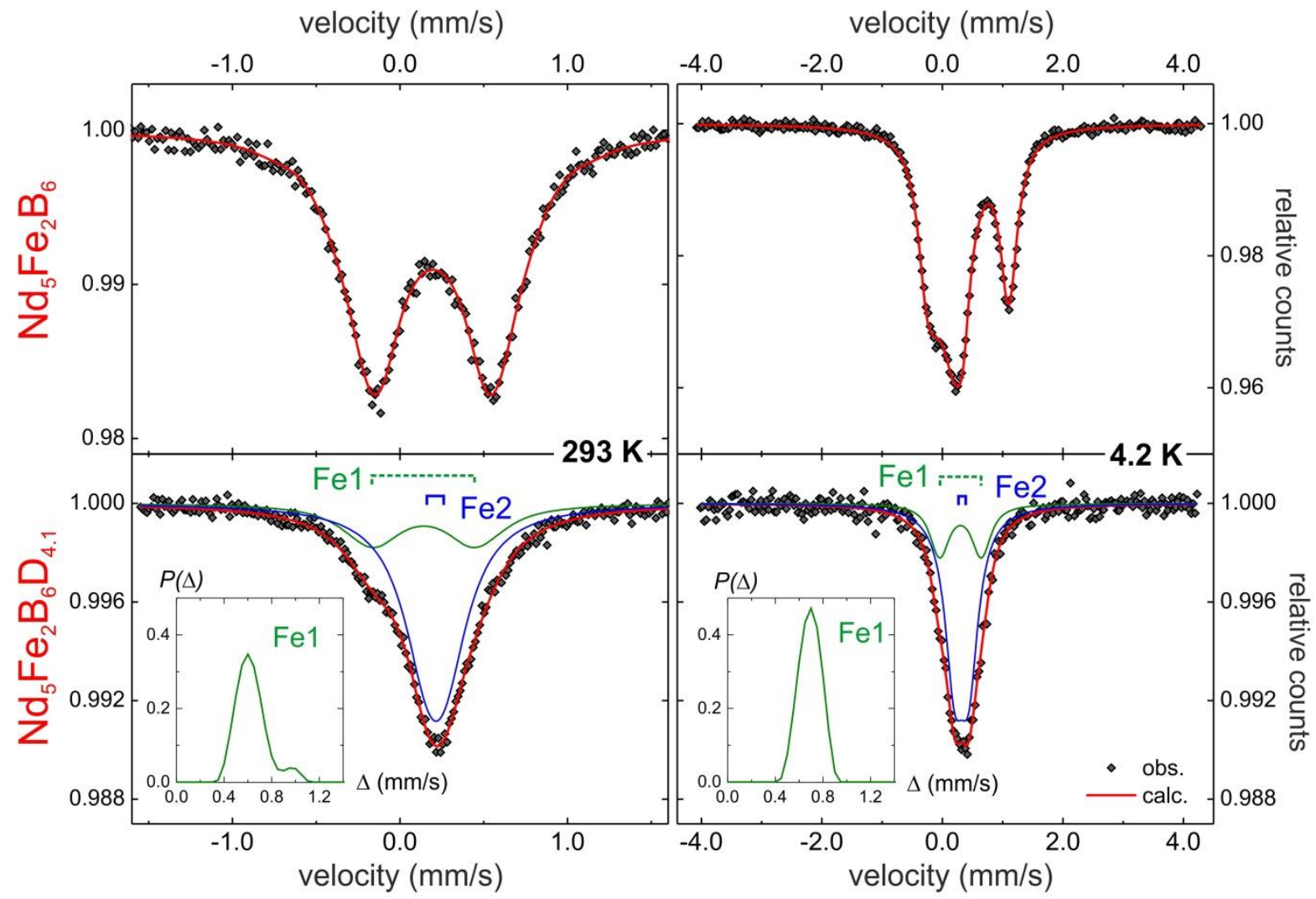

Figure 6. ${ }^{57} \mathrm{Fe}$ Mössbauer spectra of $\mathrm{Nd}_{5} \mathrm{Fe}_{2} \mathrm{~B}_{6}$ and $\mathrm{Nd}_{5} \mathrm{Fe}_{2} \mathrm{~B}_{6} \mathrm{D}_{4.1}$ recorded at room temperature (left) and $4.2 \mathrm{~K}$ (right). Insets: distributions of the quadrupole splitting. 
(a)

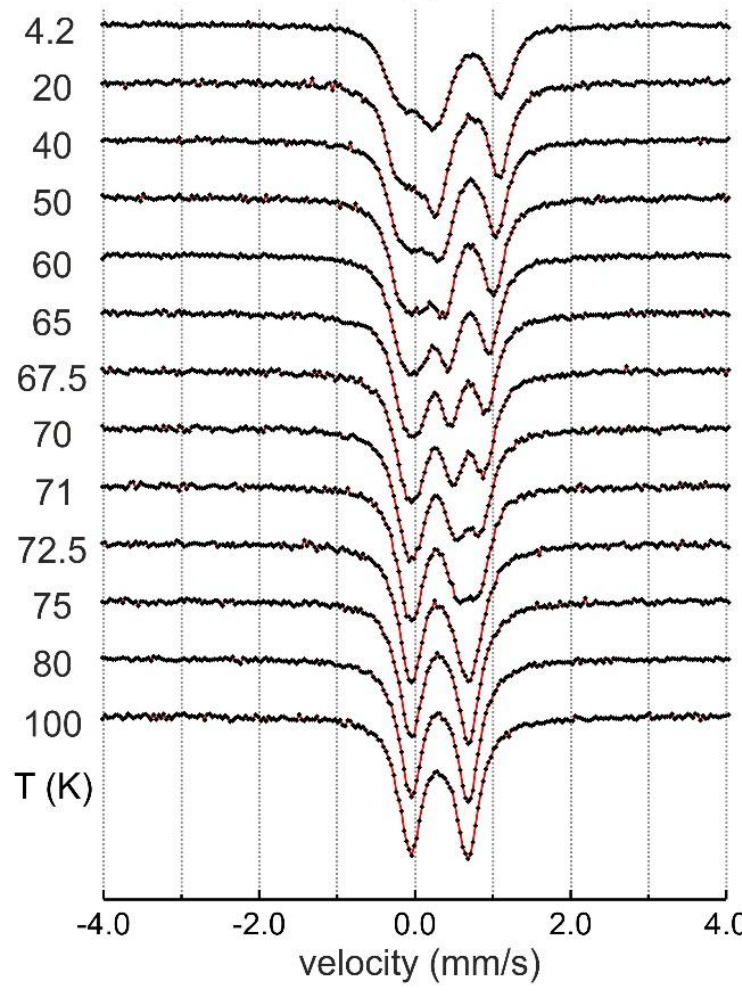

(b)

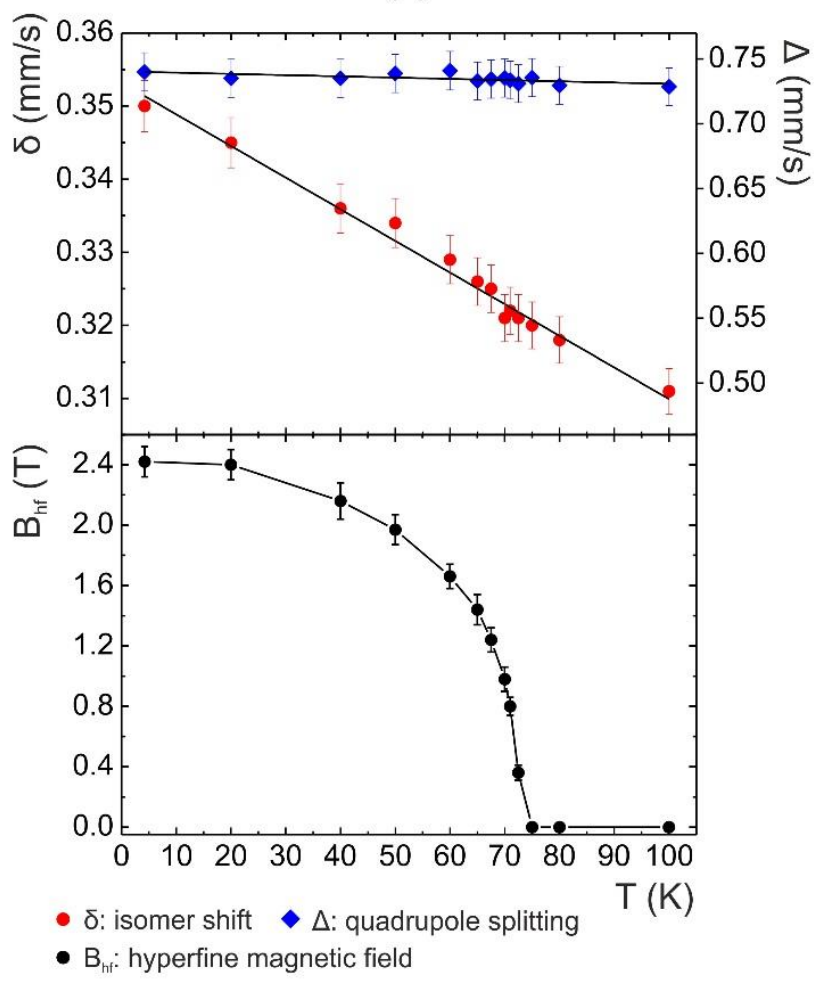

Figure 7. (a) ${ }^{57} \mathrm{Fe}$ Mössbauer spectra of $\mathrm{Nd}_{5} \mathrm{Fe}_{2} \mathrm{~B}_{6}$ recorded at various temperature from $100 \mathrm{~K}$ down to $4.2 \mathrm{~K}$. (b) Variation of the refined hyperfine parameters with temperature (solid lines are only guides to the eye). 


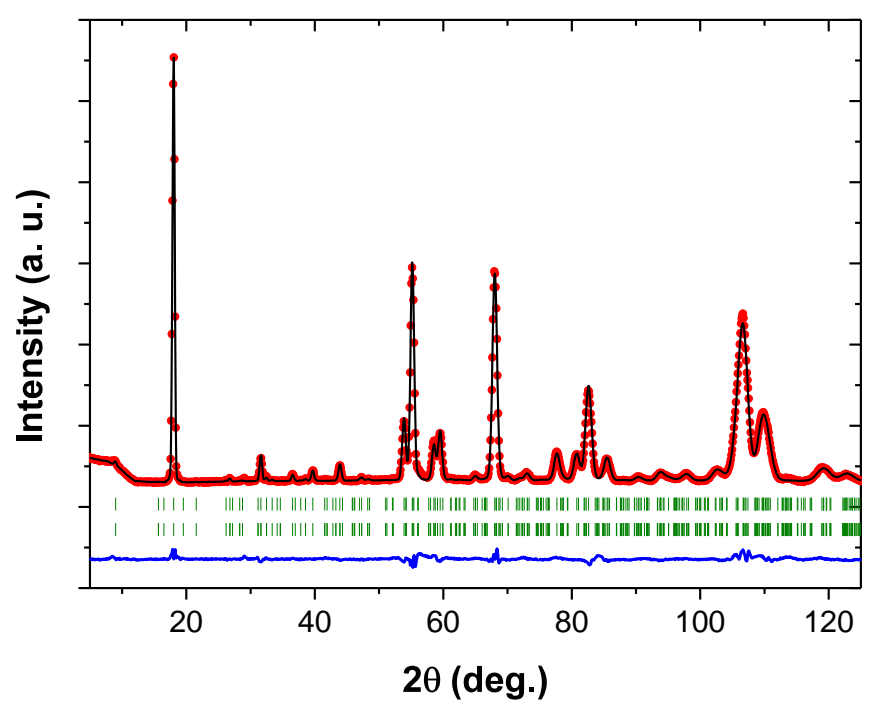

Figure 8. Neutron diffraction refinement of $\mathrm{Nd}_{5} \mathrm{Fe}_{2} \mathrm{~B}_{6}$ at $1.8 \mathrm{~K}\left(\mathrm{R}_{\mathrm{B}-\mathrm{nucl}}=4.3 \%, \mathrm{R}_{\mathrm{B}-\mathrm{mag}}=3.5 \%\right.$, $\mathrm{R}_{\mathrm{wp}}=7.0 \%$ ). The first and the second line ticks correspond to the nuclear and the magnetic Bragg positions respectively.

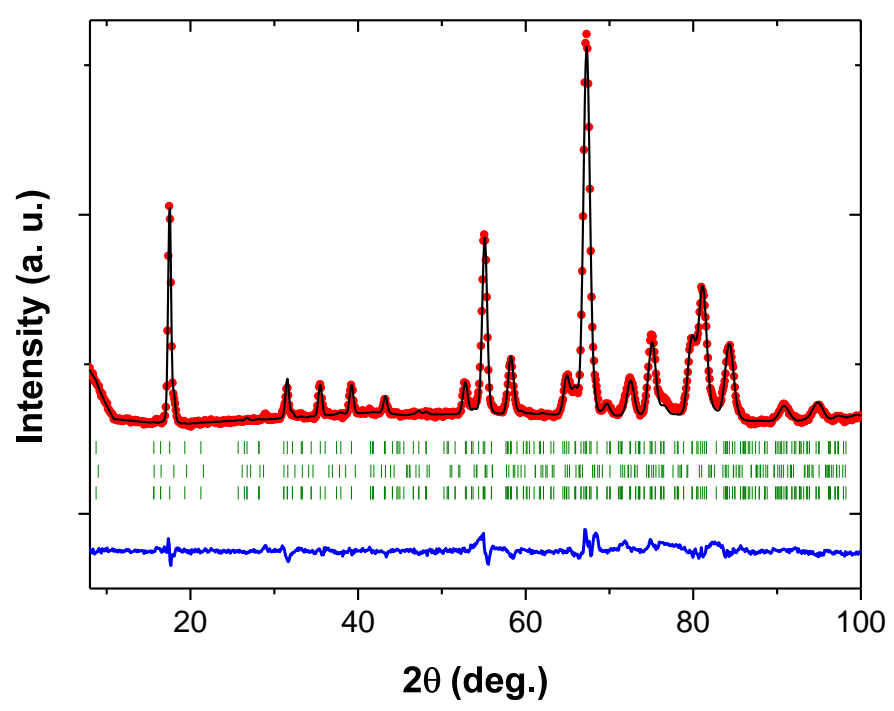

Figure 9. Neutron diffraction refinement of $\mathrm{Nd}_{5} \mathrm{Fe}_{2} \mathrm{~B}_{6} \mathrm{D}_{4.1}$ at $1.8 \mathrm{~K}\left(\mathrm{R}_{\mathrm{B} \text {-nucl }}=5.0 \%, \mathrm{R}_{\mathrm{B}-\mathrm{mag}}=13.5\right.$ $\left.\%, \mathrm{R}_{\mathrm{wp}}=9.8 \%\right)$.. The first and the third line ticks correspond to the nuclear and the magnetic Bragg positions respectively of the deuteride. The second line corresponds to the nuclear peaks of the initial boride. 

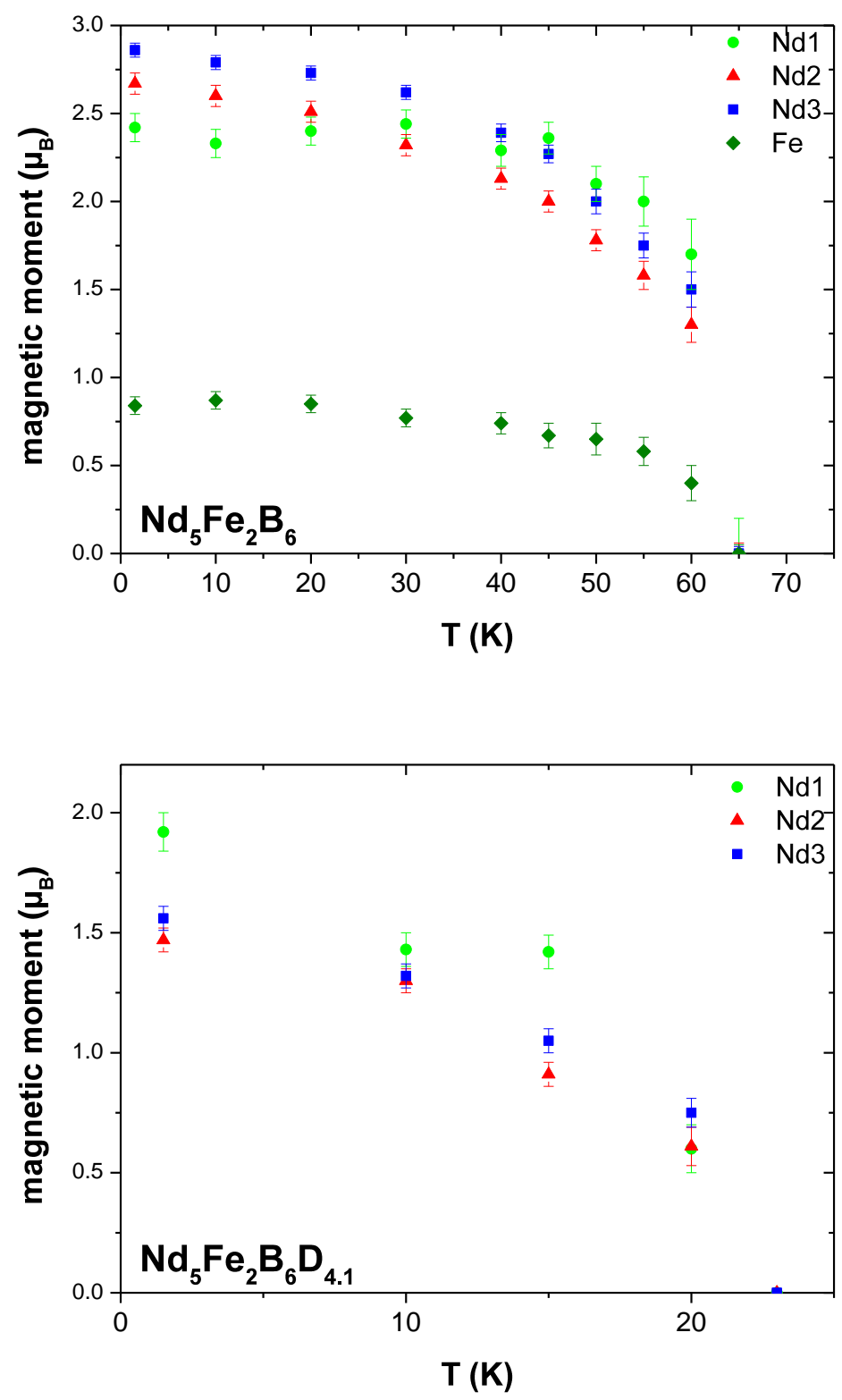

Figure 10. Thermal evolution of the magnetic moments for $\mathrm{Nd}_{5} \mathrm{Fe}_{2} \mathrm{~B}_{6}$ and $\mathrm{Nd}_{5} \mathrm{Fe}_{2} \mathrm{~B}_{6} \mathrm{D}_{4.1}$ as determined from neutron diffraction data. 


\section{Highlights}

- The structure of $\mathrm{Nd}_{5} \mathrm{Fe}_{2} \mathrm{~B}_{6} \mathrm{D}_{4.1}$ contains two interstitial sites for deuterium atoms.

- Two environments for Fe are evidenced in the deuteride by Mössbauer spectroscopy.

- The Curie temperature of $\mathrm{Nd}_{5} \mathrm{Fe}_{2} \mathrm{~B}_{6}$ is reduced after hydrogenation.

- Both $\mathrm{Nd}_{5} \mathrm{Fe}_{2} \mathrm{~B}_{6}$ and $\mathrm{Nd}_{5} \mathrm{Fe}_{2} \mathrm{~B}_{6} \mathrm{D}_{4.1}$ present a ferromagnetic structure.

- A small magnetic moment is found on iron for the boride, unlike the deuteride. 